\title{
Characterization of debonding in FRP-strengthened masonry using the acoustic emission technique
}

\author{
Bahman Ghiassi $^{1}$, Els Verstrynge ${ }^{2}$, Paulo B. Lourenço ${ }^{3}$, Daniel V. Oliveira ${ }^{4}$
}

\begin{abstract}
The acoustic emission (AE) technique is used for investigating the interfacial fracture and damage propagation in GFRP- and SRG-strengthened bricks during debonding tests. The bond behavior is investigated through single-lap shear bond tests and the fracture progress during the tests is recorded by means of AE sensors. The effect of hygrothermal conditions on the debonding characteristics and failure mode is also investigated by performing accelerated ageing tests. Accelerated ageing tests resulted in a change of failure mode in GFRP-strengthened specimens which helped in assessment of AE output in different failure modes, but no conclusive strength degradation was observed in the specimens. The results show that the average and cumulative AE energy are correlated to the FRP slip and debonding fracture energy in GFRPstrengthened specimens, respectively. The fracture progress and active debonding mechanisms are characterized using results from the AE technique. Moreover, a clear distinction between the

\footnotetext{
${ }^{1}$ Postdoctoral researcher, ISISE, University of Minho, Department of Civil Engineering, Azurém, 4800-058 Guimarães, Portugal. Phone: +351 253510 499, fax: +351 253510 217, E-mail: bahmanghiassi@civil.uminho.pt

${ }^{2}$ Dr. ir.-arch., KU Leuven, Department of Civil Engineering, Building Materials and Technology Division, Kasteelpark Arenberg 40 B-3001 Heverlee, Belgium. Phone: +32(0) 16 321987, fax: +32(0) 16 321976, E-mail: els.verstrynge@bwk.kuleuven.be

${ }^{3}$ Professor, ISISE, University of Minho, Department of Civil Engineering, Azurém, 4800-058 Guimarães, Portugal. Phone: +351 253510 209, fax: +351253 510 217, E-mail: pbl@civil.uminho.pt

${ }^{4}$ Associate Professor, ISISE, University of Minho, Department of Civil Engineering, Azurém, 4800-058 Guimarães, Portugal. Phone: +351 253510 247, fax: +351 253510 217, E-mail: danvco@civil.uminho.pt
} 
AE outputs of specimens with different failure modes, in both SRG- and GFRP-strengthened specimens, is found which allows characterizing the debonding failure mode based on acoustic emission data. The tests performed in this study are also a contribution towards the application of AE techniques for on-site health monitoring of strengthened masonry structures.

Keywords: Acoustic emission; FRP; strengthening; masonry; debonding. 


\section{Introduction}

The application of composite materials, such as Fiber Reinforced Polymers (FRPs) and Steel Reinforced Grouts (SRGs), for Externally Bonded Reinforcement (EBR) has gained increasing interest during the last years. Advantages such as low weight to strength ratio and flexibility in application have made FRPs an efficient solution for strengthening purposes. The use of steel fibers with inorganic matrices (e.g. SRGs) adds compatibility to the above mentioned advantages, providing new developments in durable strengthening of historical heritage and masonry structures [1].

The effectiveness of EBR techniques is intrinsically dependent on the bond behavior between the composite material and the masonry substrate. Therefore, understanding the involved stress transfer and fracture progress is crucial for design purposes. On the other hand, development of qualitative and quantitative bond assessment methods is necessary for structural health monitoring purposes. Significant progress has been achieved in the last years regarding experimental investigation and computational modeling of the debonding phenomenon and damage in FRP-strengthened masonry elements [1-4]. However, aspects such as failure initiation, interfacial damage propagation and localization, as well as nondestructive bond quality monitoring are still open. This paper shows how these aspects can be monitored and characterized by means of acoustic emission (AE) technique during experimental testing. A relation between the $\mathrm{AE}$ output and bond characteristics such as force-slip behavior, fracture energy, active failure mechanisms and debonding propagation provides valuable information for bond behavior assessment and numerical modeling purposes. The tests performed in this study are also a contribution towards the application of $\mathrm{AE}$ techniques for on-site health monitoring of strengthened masonry structures. 
The AE technique has been extensively used for real time detection of internal damage propagation in structural elements [5-10]. In this technique, piezoelectric sensors are used to detect high-frequency mechanical waves produced from the release of strain energy during fracture and crack propagation. It has been found that the $\mathrm{AE}$ outputs are valuable in understanding crack propagation and failure mode in laboratory tests. These findings have also made this technique interesting for on-line structural health monitoring.

The current study addresses the use of the $\mathrm{AE}$ technique in investigating the fracture process during the debonding phenomenon in masonry elements strengthened with composite materials. Single-lap shear bond tests have been performed on strengthened bricks and the interfacial fracture during the debonding tests has been monitored with $\mathrm{AE}$ sensors attached to the bricks' surface. Solid cay bricks were used as the substrate, while Glass Fiber Reinforced Polymer (GFRP) and Steel Reinforced Grout (SRG) composites were used as the strengthening materials. GFRP composites, compared with other conventional FRP materials, have lower axial stiffness which makes them more suitable for masonry structures [2]. However, durability of this strengthening technique is still under investigation. SRG has been chosen as a composite material with inorganic matrix that can be advantageous for strengthening masonry structures regarding compatibility and sustainability issues [1]. The effect of environmental conditions on the debonding phenomenon and failure modes has also been investigated in the presented study by performing accelerated ageing tests on a number of specimens before performing the debonding tests. The results obtained from the shear bond tests and the AE data are next presented and discussed. 


\section{The Acoustic Emission technique}

\subsection{General description and methodology}

Acoustic Emissions (AEs) are high-frequency transient elastic waves that are emitted within the material during local stress redistributions such as micro-crack growth. These emissions are detected on the material's surface by means of piezoelectric transducers, preamplified, filtered and amplified before being sent to the data logger. The technique has the advantage over other damage detection techniques that it relies on detection of information which is generated by the fracture process itself and allows for on-line damage detection and assessment [11].

A typical AE transient is presented in Fig.1. Background noise is eliminated through setting a minimum amplitude threshold. An AE hit with a predefined duration is recorded when the threshold is exceeded. For each AE hit, a number of parameters (e.g. arrival time, amplitude, count, duration and energy) and the waveform itself are recorded. The amount of detected AE hits and energy is influenced by the hardware used and software settings, thus software defined parameters (e.g. threshold and sampling frequency) should be kept constant for subsequent tests. The detection of acoustic emissions is also sensitive to a number of setup-specific boundary conditions, such as quality of the coupling between sensor and test specimen, attenuation and speed of wave propagation, source-sensor distance, specimen size and homogeneity.

The recorded acoustic emissions hold information on the fracture process that produced them. Basic AE hit counting, taking into account the cumulative or average number of $\mathrm{AE}$ hits, or emitted AE energy, has successfully been used for damage assessment in rock, concrete and masonry $[5,12]$. Other wave properties, such as amplitude or number of threshold crossings (counts) are also used for parameter-based analysis $[5,13]$. It is generally observed that micro- 
cracks generate a large amount of small amplitude emissions, while AE emissions from macrocracks are fewer but have higher amplitude. Based on this observation, the b-value is applied in seismic analysis to characterize the fracture process by means of the slope of the amplitude distribution [14]. Instead of the seismic b-value, an improved b-value (Ib-value), in which the number of $\mathrm{AE}$ data taken into account is set before calculation, is usually applied for $\mathrm{AE}$ applications in concrete and rock $[15,16]$.

More advanced signal-based analysis takes into account the complete AE signal allowing characterization of the fracture modes $[5,17]$. High sampling rates and the use of broadband AE sensors are required for this technique. But dedicated signal processing and interpretation can become time-consuming for large data sets. Signal-based analysis has limited application in concrete and masonry, due to the high attenuation and disturbance of the AE wave caused by the heterogeneity of the material, especially in case of masonry. As a compromise between both approaches, a simplified signal-based analysis can be applied, using the RA value and frequency to characterize the fracture process. The RA value is calculated from the ratio of the rise time (time interval between triggering time of AE signal and maximum amplitude) and the maximum amplitude. Lower average frequencies and higher RA values indicate a shift from tensile to shear nature of fracture processes $[18,19]$. Recent numerical and experimental studies have shown that the reliability of crack classification depends on the homogeneity of the material and the distance between source and sensor [20]. Heterogeneities, such as aggregates in concrete, nucleation of cracks or brick-mortar interfaces in masonry, cause dispersion and consequently alteration of the waveform. As masonry is a highly heterogeneous material, crack characterization should be performed carefully taking into account these issues. 
In this paper, it is shown that average and cumulative $\mathrm{AE}$ energy can be applied to characterize debonding phenomenon in strengthened masonry bricks when a limited number of resonance $\mathrm{AE}$ sensors are used.

\subsection{AE technique for detection of FRP debonding}

FRP debonding from masonry substrate can be accompanied by failure of the bricks, debonding in the brick-adhesive interface, debonding in the fiber-mortar interface (in case of SRG) and subsequent pull-out of the fibers or a combination of these fracture processes. In the present study, these failure mechanisms were observed in real time and characterized by means of $\mathrm{AE}$ detection. In literature, $\mathrm{AE}$ monitoring during FRP debonding from concrete beams and slabs was studied by Carpinteri [21] and by Degala [7], while shear behavior of strengthened masonry walls was analyzed by Antonaci et al. [22].

\section{Experimental program}

The experimental study focuses on detection of the interfacial damage during debonding in strengthened masonry bricks by means of the $\mathrm{AE}$ technique. The effect of environmental conditions on the bond fracture process and failure mode has also been investigated by performing accelerated ageing tests. This assisted in investigating the differences in fracture properties of the specimens with different failure modes and conditions. Single-lap shear bond tests were performed, before and after environmental exposure, for characterization of the bond behavior. Five specimens from each strengthening type and exposure conditions were tested resulting in total twenty shear bond tests. Among them, twelve specimens were tested with AE, being three reference specimens and three aged specimens for each strengthening type. 


\subsection{Materials and test specimens}

Test specimens consisted of bricks strengthened with GFRP and SRG composites. Solid clay bricks with dimensions of $200 \times 100 \times 50 \mathrm{~mm}^{3}$ were used as the substrate. The composite materials were cut with $50 \mathrm{~mm}$ width and applied to the bricks' surface along $150 \mathrm{~mm}$ length of the brick with a $40 \mathrm{~mm}$ unbounded part near the loaded end in order to minimize edge effects [1], see Fig.2.

In the GFRP-strengthened brick specimens, GFRP strips were applied to the brick surface along its centerline following the wet lay-up procedure. The bricks were dried in the oven before application of the GFRP sheets. Then, a two-part epoxy primer was applied to the bricks' surfaces for preparation of the substrate surface. Finally, a two-part epoxy resin was used as the matrix for the composite material and adhesion to the masonry substrate.

In SRG-strengthened brick specimens, a medium density steel fiber was used as the reinforcement. The steel fibers were placed on a $3 \mathrm{~mm}$ thick layer of a pozzolanic lime-based (based on an off-the-shelf dry mix) mortar which was regularized on the brick's surface. Then, another $3 \mathrm{~mm}$ mortar layer was applied to cover the steel fibers. The bricks' surfaces were sand blasted before application of the SRG in order to increase the mechanical bond between brick and mortar. Although 1 month is propose in the technical datasheets for complete curing of the mortar, the specimens were cured for three months before performing the tests.

Although recent studies have shown that the weak mortar joints can affect the bond behavior [4, 23], this issue is not well known yet. Moreover, it seems that this effect varies with material (FRP and brick) and geometrical properties [23]. Therefore, the mortar joints are neglected in this study and it is assumed that the bond strength is fully utilized on the brick's surfaces. 
Mechanical tests have been performed on the materials constituents following relevant test standards [24-27] and the results are presented in Table 1 as the mean value of five tests and the coefficients of variation $(\mathrm{CoV})$.

\subsection{Environmental exposure}

The effect of environmental exposure on the debonding behavior has been investigated by performing accelerated ageing tests. The specimens were exposed to hygrothermal conditions in a climatic chamber. The exposure consisted of $6 \mathrm{hr}$ temperature cycles from $+10^{\circ} \mathrm{C}$ to $+50^{\circ} \mathrm{C}$ and constant relative humidity of $60 \%$, see Fig.3. In each cycle, the temperature was kept constant at $+10^{\circ} \mathrm{C}$ for $2 \mathrm{hr}$. It was then increased to $+50^{\circ} \mathrm{C}$ in $1 \mathrm{hr}$, followed by $2 \mathrm{hr}$ constant temperature at $+50^{\circ} \mathrm{C}$. Then, the temperature was decreased again to $+10^{\circ} \mathrm{C}$ in $1 \mathrm{hr}$ resulting in $6 \mathrm{hr}$ cycles of exposure. The specimens were exposed to 180 cycles in total ( 45 days).

The aim was to investigate to simulate the environmental conditions in regions with average relative humidity conditions. Therefore, due to the short exposure time considered in this study, the thermal mismatch between epoxy resin and glass fibers/brick is expected to be the governing degradation mechanism in the specimen.

\subsection{Experimental setup}

Single-lap shear bond tests were performed to investigate the bond behavior in the reference and aged specimens. The tests were performed using a closed-loop servo-controlled testing machine with maximum load capacity of $50 \mathrm{kN}$. A rigid supporting steel frame was used to support the specimens appropriately and avoid misalignments in the load application. The specimens were placed on the steel frame and firmly clamped to it as shown in Fig.4(a). The

specimens were pulled monotonically with a rate of $5 \mu \mathrm{m} / \mathrm{sec}$ under displacement control 
conditions with reference to the LVDT placed at the loaded end of the FRP composite. The resulting load was measured by means of a load cell. The relative slip between the composite material and the brick was measured with the two LVDTs glued at the loaded end and one glued at the free end, see Fig.4(b).

Acoustic emissions were monitored using a 4-channel Vallen AMSY-5 system with 150$500 \mathrm{kHz}$ operation frequency and $5 \mathrm{MHz}$ sampling rate. Four $150 \mathrm{kHz}$ resonance sensors were attached to opposite sides of the bricks by means of hot melt glue, see Fig.4(b). The preamplifier gain was set to $34 \mathrm{~dB}$ with a fixed threshold level of $40 \mathrm{~dB}$ and pencil lead breaks were used for system calibration [28]. To calculate the AE energy, the AE signal is squared and integrated and the energy unit (eu) is given by $1 \mathrm{eu}=10^{-14} \mathrm{~V}^{2} \mathrm{~s}$. Definitions of energies are different in $\mathrm{AE}$ system suppliers, but it is generally defined as a measured area under the rectified signal envelope (MARSE) [5]. Here, the squared signal is the standard setting in the equipment for calculating the RMS and has been used for all the tests.

\section{Results and discussion}

\subsection{Debonding behavior}

The envelope of the force-slip curves obtained from the experimental tests is shown in Fig.5 for the reference and aged specimens. The lack of a horizontal branch before the load drop in the envelope of SRG-brick specimens, Fig.5(b), shows that the bonded length can possibly be shorter than the effective bond length. A slight $6 \%$ reduction of the average maximum debonding

force can be observed in GFRP-strengthened brick specimens after exposure to environmental conditions, which contrasts with a significant $27 \%$ reduction for SRG-strengthened brick specimens. The initial bond stiffness, defined as the initial slope of the force-slip curves, does not 
show any relevant change. Although there is not enough information available regarding the durability of FRP-brick or SRG-brick systems, in general, lower degradation is expected in SRGbrick specimens due to the expected compatibility between the mortar and brick substrate. However, there are several factors that can considerably affect the durability of SRG-brick systems such as mortar type, mortar thickness and mortar-steel compatibility. FRP-brick specimens may show large degradations when exposed to high humid environments which is not the case of this study, temperature cycles of 10 to 50 and $60 \%$ R.H. In case of SRG-brick specimens, the above mentioned factors may have resulted in the mortar cracking and consequently the observed drop in the peak load. However, due to the small number of tests and short exposure period, no definitive conclusions can be made about the degradation of the specimens at this stage.

The summary of the test results is presented in Table $\mathbf{2}$ in terms of the average maximum debonding force. It can be observed that the Coefficient of Variation $(\mathrm{CoV})$ of the reference GFRP-brick specimens is very low (5.3\%), while for the aged specimens this value is larger (20.6\%). The CoVs of the results in SRG-strengthened specimens were equal to $14.4 \%$ and $20 \%$ for reference and aged specimens, respectively.

In terms of failure mode, a change from cohesive failure to adhesive failure after exposure to accelerated tests was observed in the GFRP-brick specimens. The observed failure modes in the reference specimens were cohesive failure with fracture inside the brick (1 specimen) or a combination of cohesive/adhesive failure ( 2 specimens), see Fig.6(a, b). The cohesive fracture occurred in a relatively deep layer of the brick (around $10 \mathrm{~mm}$ ). The contribution of the adhesive failure in the specimens with mixed failure mode was relatively small (around $20 \%$ of the bonded area). On the other hand, the failure mode in the aged 
specimens was predominantly adhesive. The fracture surface was at the FRP/brick interface in all three specimens, see Fig.6(c). The adhesive failure was combined with detachment of a brick bulb at the free end in two specimens, see Fig.6(d). The observed change of failure mode after exposure to hygrothermal conditions can be attributed to the degradation of interface properties due to thermal incompatibility problem and induced thermal fatigue on the specimens [29].

In SRG-strengthened brick specimens, two failure modes were observed: (a) steel fibers slipping and mortar cover separation, which was the main observed failure mode, Fig.7(a); (b) detachment of mortar from the brick's surface, Fig.7(b), which happened only in one reference specimen.

\subsection{Characterization of damage by means of AE output}

Typical AE results obtained from the debonding tests on GFRP-strengthened brick specimens are shown in Fig.8. The reported results focus on the overall recorded activity, with possible noise source detection reduced by means of amplitude threshold setting and a fixed frequency band pass. The results are presented for a reference specimen with mixed cohesive/adhesive failure mode, in terms of cumulative AE energy and hits together with the force and slip development during the tests. The cumulative AE energy to hit ratio, called $\mathrm{E} / \mathrm{h}$ hereafter, has also been investigated and the results are presented.

Generally, the debonding phenomenon can be divided into three main regions: elastic range, micro-cracking range, macro-cracking and fracture range. In the elastic range, the system deforms without any crack generation and $\mathrm{AE}$ activities. The displacement measured at this stage is small being due to the elastic deformation of the FRP composite. "Cracking" occurs at the moment in which the applied stresses reach the material's cohesive strength, but given the inhomogeneity of the material, microcracking is present since the beginning and the coalescence 
in macrocraks is a truly complex discussion, outside the scope of the paper. Therefore, until this stress level, the applied load causes elastic deformation in the system and the detect AE energies are negligible. As the applied force increases, micro-cracks appear in the interfacial region and they can be distinguished by initiation of AE activity with low emitted energies, e.g. after 100 sec of the test in Fig.8(a, b). From this point the debonding progresses through the weakest line inside the material or at the interface. The onset of $\mathrm{AE}$, which here can be considered as the boundary between the elastic region and the microcracking region, can be of great interest for detailed micro-modeling approaches. This transition point for the GFRP-brick specimens occurs when the applied load is around $1.5 \mathrm{kN}$, see Fig.8(a). Since the fracture energy release due to the formation of micro-cracks is relatively small, low values of AE energies are expected in this region, see Fig.8(a). The rate of detected AE hits is higher than the AE energy rate at this stage, resulting in a descending E/h, which indicates the formation of micro-cracks, see Fig.8(c). As the debonding progresses, macro-cracks are formed and propagated along the interface with higher fracture energy being released. Therefore, higher AE energy is detected in this region. The cumulative AE energy increases with a stepwise pattern in which each sudden jump of energy can be correlated to a sudden fracture energy release and can thus be attributed to macro-fracture events, see Fig.8(a, d). A sudden release of a high amount of AE energy can also be observed at the moment of full debonding, coinciding with the end of the test. The E/h ratio, Fig.8(c), shows that each stage of the progressive debonding starts with a high rate of energy release (observed as a sudden jump in the $\mathrm{E} / \mathrm{h}$ curve) and continues with a descending rate until the end of each stage. The sudden jumps in E/h curve, in macro-fracture range, are due to the formation of macrocracks with high energy release. Fig.8(d) shows a clear correlation between slip increment and cumulative AE energy. This correlation can be used for predicting the FRP slip or debonding 
fracture energy in FRP-strengthened masonry elements, as explained in Section 4.4. A slip decrement is observed in the FRP at around $700 \mathrm{sec}$ of the test, see Fig.8(d). As explained before, LVDTs are used during the debonding tests for measurement of FRP slip form the brick substrate. LVDTs are mounted on the brick surface as the reference point and the displacements are measured relative to a support mounted on the FRP surface. During the delamination tests, it is possible that the FRP moves out of plane (normal to the brick surface) due to the macro debonding or fracture of the brick. This, which takes few seconds until FRP readjusts itself, can result in diverse readings in LVDTs, as is the case in this test.

The effect of failure mode on the AE outputs is investigated in Fig.9. A clear distinction is found between $\mathrm{AE}$ outputs of specimens with different failure modes. It can be observed that in the specimen with cohesive debonding AE energy remain relatively low throughout the test, accompanied by a sudden and large amount of $\mathrm{AE}$ energy release and increase of $\mathrm{E} / \mathrm{h}$ ratio when the debonding occurs at the end of the test, see Fig.9(a). The observed behavior confirms the brittle and sudden nature of the cohesive debonding. Fewer peaks are observed in the $\mathrm{E} / \mathrm{h}$ curve compared to the specimen with cohesive/adhesive debonding. At the end, a macro-crack with a high amount of energy release has suddenly occurred, leading to the complete debonding of the FRP. On the contrary, in the specimen with cohesive/adhesive failure a progressive release of energy is observed during the test. The high rate of energy detection shows the high number of active cracks and progressive failure during the tests. In the specimen with adhesive debonding mode, Fig.9(b), progressive detection of AE energies is observed until the complete debonding. However, the magnitude of the detected energies is much lower than the ones detected in the specimens with cohesive failure mode. This large difference is due to the different nature and fracture properties of brick and FRP/brick interface. The specimen with adhesive failure 
combined with formation of a brick bulb at the free end shows a similar AE energy emission to the specimen with pure adhesive failure. However, a large amount of energy is released in this specimen before debonding due to the brick bulb fracture at the free end.

Fig.10 presents a typical result obtained from a SRG-strengthened brick specimen, which failed with slipping of the steel fibers and mortar cover separation. Mainly, three regions representing different mechanisms can be observed during the debonding process. AE activities before the first cracking of the mortar are negligible. During mortar cracking, the rate of $\mathrm{AE}$ activities increases and high AE energy is detected as the force increases, see Fig.10(a). The resisting mechanisms in this region are adhesive bond and friction (mechanical interlocking) between the steel fiber and mortar. Since the surface of the steel fibers used in this study is twisted, mechanical interlocking exists between the steel fibers and the mortar at their interface providing resistance against the pull-out action. Detachment of the bond is accompanied by releasing relatively high fracture energies, being observed as the sudden jumps in the $\mathrm{AE}$ cumulative energy curve. A high rate of AE activities is observed in this region, Fig.10(b), and the rate of detected AE energy is larger than AE hits, Fig.10(c). As the debonding progresses, the bond diminishes and friction governs the failure mechanism resulting in reduction of the detected AE energy rate. The rate of AE hits continues to increase, Fig.10(b), resulting in a descending trend in E/h ratio, Fig.10(c). The debonding occurs with a sudden force reduction and slip increase, which is coincident with a sudden increase in $\mathrm{AE}$ activity and decrease in $\mathrm{E} / \mathrm{h}$ ratio. Contrary to the GFRP-strengthened specimens, no direct relation can be observed between the measured slip and AE cumulative energy in the SRG-strengthened brick specimens. However, the existence of a correlation between the debonding fracture energy and the total emitted $\mathrm{AE}$ energy is expected. Here, the onset of AE is occurred when the load is around $0.5 \mathrm{kN}$. 
A comparison is made between two reference specimens with different failure modes, namely brick/mortar detachment and fibers slipping, see Fig.11. A brittle behavior is observed in the specimen with brick/mortar detachment failure. The detected AE energy level in this specimen is very low during the test followed by a sudden release of energy at the moment of debonding. A similar trend is also observed in the E/h ratio, see Fig.11(b). On the other hand, the fibers slipping failure mode produces a progressive release of energy during the test until diminishing the adhesive bond, followed by a reduction of the AE energy rate in the stage governed by frictional resistance. The slope of the E/h ratio also changes with the change in the failure mechanisms as described before.

\subsection{Remarks on other methods for failure characterization analysis}

In the previous section, the $\mathrm{AE}$ energy release rate was used for failure mode analysis and a correlation was found between the $\mathrm{AE}$ energy outputs and the debonding behavior. As indicated in Section 2, other methodologies have been developed in the literature for discrimination between different fracture modes and may be of interest in debonding tests. A review of the applicability of these methods is presented and discussed in this section. RA value and frequency analysis are not presented, since for the tests performed, no reliable deductions could be made from these results regarding the failure mode characterization. The reason is that the tests were performed with resonance sensors and the test specimens were not isotropic and relatively small with regard to the wavelength. Distortion of the frequency spectra and of the waveforms strongly affects the accuracy of the results in these analysis techniques. In literature, good results on frequency analysis in larger masonry specimens were achieved by using wide band AE transducers [30]. 
An Ib-value (Improved b-value) analysis was performed on the obtained data from AE detection. The Ib-value represents the ratio between weak (low amplitude, micro-cracking) and strong (high amplitude, macro-cracking) events. It is calculated as the slope of the cumulative distribution of the amplitudes of a preset number of hits. In general, the fracture shifts from micro- to macro-cracking upon monotonic stress increase and the Ib-value decreases. The graphs presented in Fig.12 are calculated according to the formula proposed by Shiotani [15] and applied e.g. by Aggelis [18]:

$$
I b=\frac{\log _{10} N\left(\mu-\alpha_{1} \cdot \sigma\right)-\log _{10} N\left(\mu+\alpha_{2} \cdot \sigma\right)}{\left(\alpha_{1}+\alpha_{2}\right) \cdot \sigma}
$$

with $\sigma$ being the standard deviation and $\mu$ being the mean value of the amplitudes of a group of AE hits. Usually, a group of 50 or 100 hits is chosen (the latter is chosen here, $N$ ). The Ib-value is updated after every 10 new hits and $\alpha_{1}$ and $\alpha_{2}$ are constants related to the minimum and maximum amplitude level. For each subsequent group of AE hits, the cumulative amplitude distribution is applied and the logarithm is taken of the cumulative value corresponding to the lower and upper amplitude values $\left(\mu-\alpha_{1} \sigma\right)$ and $\left(\mu+\alpha_{2} \sigma\right)$ respectively.

Fig.12 presents the evolution of the Ib-value calculated for the GFRP-strengthened brick specimens with different failure modes. In general, the graphs have many peaks and the average Ib-value does not decrease towards the end of the test as is generally observed in compression and bending tests [18]. This can be explained by the nature of the fracture process under analysis, which is not a general shift from micro to macro-cracking. Since the bonded area fails progressively, a sequence of stress buildup (micro-cracking) and debonding (macro-cracking) occurs. This results in high and low amplitude hits occurring almost at equal density throughout the test. 
In the specimen with cohesive failure, Fig.12(a), the macro-cracks are accompanied by a sudden decrease in Ib-value as expected. The lb-value trend shows that this failure mode is accompanied by few large cracks and sudden release of energy at the debonding moment. The lb-value in the cohesive/adhesive failure, Fig.12(b), presents many drops during the test showing that the active failure is a combination of macro- and micro-fracture during the tests. The debonding has occurred with a progressive formation of large and small cracks. Although macrofractures are distinguishable during the test, a decreasing trend in average lb-value is not observed, comparable to the specimen with cohesive failure. In the specimen with adhesive failure, Fig.12(c), decreases in the average lb-value can be observed when moving from microto macro-cracking range. The observed drops in the lb-value in macro-fracture range confirm the progressive nature and fracture release in this failure mode. The formation of the brick bulb at the free end is also observable at the end of the test in the other specimen, Fig.12(d).

Although the micro- and macro-fracture can be distinguished from the lb-value analysis, the results are not very clear due to the large number of observed peaks and the fact that no general decreasing trend can be observed. For fracture mode characterization, the technique shows limited added value for short-term debonding tests as performed in this research. The technique can be of more interest during long-term debonding tests as the occurrence of macrocracking might be more rare and alternated with long periods of no or only weak AE activity. On the contrary, the AE energy rate analysis, as presented in the previous section, was shown to be a valuable tool for characterizing the debonding phenomenon in FRP-strengthened masonry and also onsite structural health monitoring purposes. 


\subsection{Predicting the bond parameters with AE outputs}

The experimental results, presented in Section 4.2, showed that the debonding fracture energy can be correlated with the total emitted AE energy. It should be noted that the debonding fracture energy is the energy required for the occurrence of debonding along a unit length of the bonded elements. Meanwhile, the acoustic energy is the energy of the acoustic waves released from the specimens due to debonding. Although these parameters are not comparable, it has been observed that some correlation may exist between them [5]. Moreover, it was observed that the AE energy rate shows a trend similar to the FRP slip in FRP-strengthened brick specimens. In this regard, presenting a relation between these bond parameters and the AE outputs can be interesting for numerical modeling or structural health monitoring purposes. In this section, these relations are obtained from the experimental tests. Proposing a comprehensive relation between AE outputs and debonding parameters requires an extensive experimental program and thus the observations reported here can be seen as a first step towards this aim.

Fig.13 presents the FRP global slip in GFRP-strengthened specimens and the cumulative AE energy. A regression analysis has been performed for obtaining a relation between the FRP slip and the AE energy. Since the fracture process, crack propagation and FRP slip change with the failure mode, different relations are proposed for adhesive and (mostly) cohesive debonding. For the adhesive failure, the results obtained from the only specimen with pure adhesive failure are considered in the analysis and the rest of the specimens are considered in the regression analysis for the (mostly) cohesive failure modes. A linear relation seems suitable for both failure modes $\left(\mathrm{R}^{2}=0.93\right.$ for adhesive failure and $\mathrm{R}^{2}=0.96$ for cohesive failure). This relation is can then be used as a new tool for obtaining the FRP slip in debonding tests. 
The debonding fracture energy is an important parameter for numerical modeling of the bond behavior. This parameter is usually obtained from the experimental tests by using strain gauges [3]. It is also possible to obtain this parameter from the maximum debonding force as follows [31]:

$G_{f}=\frac{P_{\max }^{2}}{b_{f}^{2}\left(2 E_{f} t_{f}\right)}$

where, $P_{\max }$ is the debonding force, $b_{f}$ is the FRP width, $E_{f}$ is the FRP elastic modulus, and $t_{f}$ is the FRP thickness. The fracture energy of the GFRP-strengthened specimens have been obtained according to Eq (2) for different failure modes and are presented together with the corresponding total emitted AE energy in Table 3. Again, the value for the adhesive failure mode is obtained from the only specimen with pure adhesive failure, while the values presented for cohesive failure are the average of the specimens with (mostly) cohesive failure modes. It can be observed that the total emitted AE energy and the fracture energy in cohesive failure mode are much larger than in adhesive failure mode, as expected. However, obtaining an accurate relation between the fracture energy and AE emitted energy is not possible at this point due to the limited number of experimental results.

The results indicate the applicability of $\mathrm{AE}$ output for characterization of the failure modes in FRP-strengthened masonry. The presented methodology, applied on experimental data, is also promising for on-site applications.

\section{Conclusions}

The AE technique was applied to detect and characterize fracture and crack propagation during the debonding of composite materials from masonry bricks. The specimens consisted of 
solid clay bricks strengthened with GFRP and SRG composites. The debonding phenomenon was investigated by performing single-lap shear bond tests on the specimens. In order to obtain different values of bond strength and failure mode, accelerated ageing tests were also carried out. The failure mode of the GFRP-strengthened specimens changed after exposure from cohesive to adhesive failure which assisted in evaluating the AE applicability in detecting different failure modes. This can be helpful in interpretation of structure condition during laboratorial testing or onsite health monitoring.

The results showed that $\mathrm{AE}$ output can be efficiently used for investigation and interpretation of the fracture process during debonding. AE data, and more specifically the detected AE energy, was applied to characterize the different failure modes. Thereby, the cumulative energy/hit (E/h) ratio and Ib-value analysis were applied. While the AE energy could effectively be applied for failure mode characterization, the $\mathrm{Ib}$ value analysis was inconclusive due to the progressive nature of the fracture process during debonding. A correlation was observed between the fracture energy and total emitted AE energy. Moreover, a close correlation was found between the FRP global slip and the cumulative AE energy, which can be applied for slip prediction and modeling purposes. The effect of failure mode on the AE outputs was significant in both GFRP- and SRG- strengthened specimens.

The results indicate that the $\mathrm{AE}$ technique is suitable for obtaining a clearer insight into the debonding phenomenon and fracture propagation in laboratory tests and has potential for onsite health monitoring through debonding detection. Although performing a comprehensive experimental program for a better understanding of the advantages of the technique and establishing correlations between fracture properties an AE outputs is necessary. 


\section{Acknowledgements}

The first author acknowledges the financial support of the Portuguese Science Foundation (Fundação de Ciência e Tecnologia, FCT), through grant SFRH/BD/80697/2011.

\section{References}

[1] Valluzzi MR, Oliveira DV, Caratelli A, Castori G, Corradi M, de Felice G, et al. Round robin test for composite-to-brick shear bond characterization. Mater Struct. 2012;45:1761-91.

[2] Oliveira D, Basilio I, Lourenço P. Experimental bond behavior of FRP sheets glued on brick masonry. J Compos Constr, ASCE. 2011;15:32-41.

[3] Ghiassi B, Marcari G, Oliveira DV, Lourenço PB. Numerical analysis of bond behavior between masonry bricks and composite materials. Eng Struct. 2012;43:210-20.

[4] Fedele R, Milani G. A numerical insight into the response of masonry reinforced by FRP strips. The case of perfect adhesion. Compos Struct. 2010;92:2345-57.

[5] Grosse CU, Ohtsu M. Acoustic emission testing - basics for research - applications in civil engineering. Springer; 2008.

[6] Colombo S, Main I, Forde M. Assessing damage of reinforced concrete beam using " bvalue" analysis of acoustic emission signals. J Mater Civil Eng. 2003;15:280-6.

[7] Degala S, Rizzo P, Ramanathan K, Harries KA. Acoustic emission monitoring of CFRP reinforced concrete slabs. Constr Build Mater. 2009;23:2016-26.

[8] Kordatos EZ, Aggelis DG, Matikas TE. Monitoring mechanical damage in structural materials using complimentary NDE techniques based on thermography and acoustic emission. Compos Part B. 2012;43:2676-86. 
[9] Carpinteri A, Lacidogna G. Damage evaluation of three masonry towers by acoustic emission. Eng Struct. 2010;29:1569-79.

[10] Nair A, Cai CS. Acoustic emission monitoring of bridges: review and case studies. Eng Struct. 2010;32:1704-14.

[11] Wevers M. Listening to the sound of materials: Acoustic emission for the analysis of material behavior. Ndt E Intern. 1997;30:99-106.

[12] Tomor AK, Verstrynge E. A joint fatigue - creep deterioration model for masonry with acoustic emission based damage assessment. Constr Build Mater. 2013;43:575-88.[13] Eberhardt E, Stead D, Stimpson B, Read RS. Changes in acoustic event properties with progressive fracture damage. Int J Rock Mech \& Min Sci. 1997;34.

[14] Carpinteri A., Lacidogna G., S. P. From criticality to final collapse: Evolution of the b-value from 1.5 to 1.0. Chaos, Solitons and Fractals. 2009;41:843-53.

[15] Shiotani T, Yuyama S, Li ZW, Ohtsu M. Quantitative evaluation of fracture processes in concrete by the use of improved b-value. Non-Destruct Test Civil Eng. 2000:293-302.

[16] Kurz JH, Finck F, Grosse CU, Reinhardt HW. Stress drop and stress redistribution in concrete quantified over time by the b-value analysis. Struct Health Monit. 2006;5:69-81. [17] Grosse CU, Finck F. Quantitative evaluation of fracture processes in concrete using signalbased acoustic emission techniques. Cem Conc Compos. 2006;28:330-6.

[18] Aggelis DG, Soulioti DV, Sapouridis N, Barkoula NM, Paipetis AS, Matikas IE. Acoustic emission characterization of the fracture process in fibre reinforced concrete. Constr Build Mater. 2011;25:4126-31. 
[19] Soulioti D, Barkoula NM, Paipetis A, Matikas TE, Shiotani T, Aggelis DG. Acoustic emission behavior of steel fibre reinforced concrete under bending. Constr Build Mater. 2009;23:3532-6.

[20] Aggelis DG, Shiotani T, Papacharalampopoulos A, Polyzos D. The influence of propagation path on elastic waves as measured by acoustic emission parameters. . Struct Health Monit-an Intern J. 2012;11:359-66.

[21] Carpinteri A, Lacidogna G, Paggi M. Acoustic emission monitoring and numerical modeling of FRP delamination in RC beams with non-rectangular cross-section. Mater Struct. 2007;40:553-66.

[22] Antonaci P, Bocca P, Masera D. Fatigue crack propagation monitoring by Acoustic Emission signal analysis. Eng Frac Mech. 2012;81:26-32.

[23] Ghiassi B, Oliveira DV, Lourenço PB, Marcari G. Numerical study of the role of mortar joints in the bond behavior of FRP-strengthened masonry. Compos Part B. 2012;46:21-30. [24] EN 772-1. Methods of test for masonry units -Part 1: Determination of compressive strength; 2011.

[25] EN ISO 527-1. Plastics-determination of tensile properties- Part 1: general principles. 1993. [26] EN 1015-11. Methods of test mortar for masonry Part 11: Determination of flexural and compressive strength of hardened mortar. 2007.

[27] ASTM D7565-10. Standard test method for determining tensile properties of fiber reinforced polymer matrix composites used for strengthening of civil structures. 2010. [28] EN 13477-2 Non-destructive testing. Acoustic emission. Equipment characterisation. Verification of operating characteristic. 2010.

[29] Karbhari VM. Durability of composites for civil structural applications. CRC Press; 2007. 
[30] Masera D, Bocca P, Grazzini A. Frequency Analysis of Acoustic Emission Signal to Monitor Damage Evolution in Masonry Structures. 9th DAMAS2011. p. 305.

[31] CNR-DT 200. Guide for the design and construction of externally bonded FRP systems for strengthening existing structures. CNR-DT 200/2004. Rome: National Research Council; 2004. 


\section{List of Tables}

Table 1. Material mechanical properties.

Table 2. Average debonding force of the tested specimens.

Table 3. Fracture energy and AE energy in different failure modes for GFRP-strengthened specimens.

\section{List of Figures}

Fig.1. Typical AE transient event with indication of wave characteristics.

Fig.2. Details of the specimens prepared for debonding tests (dimensions in $\mathrm{mm}$ ): Plan view.

Fig.3. Hygrothermal exposure.

Fig.4. (a) Test setup; (b) test instrumentation.

Fig.5. Envelope of experimental force-slip behavior in the reference and aged specimens: (a) GFRP-strengthened bricks; (b) SRG-strengthened bricks.

Fig.6. Observed failure modes in GFRP-strengthened brick specimens: (a) cohesive failure with fracture inside brick; (b) cohesive-adhesive failure; (c) adhesive failure at the FRP/brick interface; (d) adhesive failure with a brick bulb at the free end.

Fig.7. Observed failure modes in SRG-strengthened brick specimens: (a) steel fibers slipping and mortar cover separation; (b) mortar-brick interface debonding

Fig.8. Typical AE results in reference GFRP-strengthened brick specimens: (a) force-cumulative AE energy; (b) force-cumulative AE hits; (c) force-energy/hits, E/h; (d) slip-cumulative AE energy.

Fig.9. Comparison of different failure modes in GFRP-strengthened bricks: (a) cohesive debonding; (b) adhesive debonding.

Fig.10. Typical AE results in reference SRG-strengthened brick specimens: (a) force-cumulative $\mathrm{AE}$ energy; (b) force-cumulative AE hits; (c) force-energy/hits, $\mathrm{E} / \mathrm{h}$; (d) slip-cumulative $\mathrm{AE}$ energy.

Fig.11. Comparison of different failure modes in SRG-strengthened bricks: (a) cumulative AE energy; (b) E/h ratio.

Fig.12. Ib-value analysis for GFRP-strengthened brick specimens with (a) cohesive failure; (b) cohesive/adhesive failure; (c) adhesive failure; (d) adhesive failure with brick bulb.

Fig.13. Correlations between slip and cumulative AE energy in GFRP-strengthened specimens. 
Table 1. Material mechanical properties.

\begin{tabular}{|c|c|c|c|}
\hline & & $\begin{array}{l}\text { Mean } \\
\text { value }\end{array}$ & $\operatorname{CoV}(\%)$ \\
\hline \multicolumn{4}{|l|}{ Masonry brick } \\
\hline Compressive strength & $f_{\mathrm{cb}}(\mathrm{MPa})$ & 14.2 & 4.0 \\
\hline Flexural tensile strength & $f_{\mathrm{tb}}(\mathrm{MPa})$ & 1.6 & 12.0 \\
\hline \multicolumn{4}{|l|}{ GFRP coupons } \\
\hline Tensile strength & $f_{\mathrm{tf}}(\mathrm{MPa})$ & 1250.0 & 15.0 \\
\hline Elastic modulus & $E_{\mathrm{f}}(\mathrm{GPa})$ & 79.2 & 6.8 \\
\hline Ultimate strain & $\varepsilon(\%)$ & 3.0 & 20.3 \\
\hline \multicolumn{4}{|l|}{ Epoxy resin } \\
\hline Tensile strength & $f_{\mathrm{tm}}(\mathrm{MPa})$ & 55.3 & 9.7 \\
\hline Elastic modulus & $E_{\mathrm{m}}(\mathrm{GPa})$ & 2.9 & 9.5 \\
\hline \multicolumn{4}{|l|}{ Primer } \\
\hline Tensile strength & $f_{\mathrm{tm}}(\mathrm{MPa})$ & 54.1 & 11.1 \\
\hline Elastic modulus & $E_{\mathrm{m}}(\mathrm{GPa})$ & 2.4 & 6.1 \\
\hline \multicolumn{4}{|l|}{ Mortar } \\
\hline Compressive strength (28 days) & $f_{\mathrm{cm}}(\mathrm{MPa})$ & 12.7 & 10.1 \\
\hline \multicolumn{4}{|l|}{ Steel fibers } \\
\hline Tensile strength & $f_{\mathrm{ts}}(\mathrm{MPa})$ & 2980.0 & 2.9 \\
\hline Elastic modulus & $E_{\mathrm{s}}(\mathrm{GPa})$ & 190.0 & 8.8 \\
\hline Ultimate strain & $\varepsilon(\%)$ & 1.60 & 14.0 \\
\hline
\end{tabular}


Table 2. Average debonding force of the tested specimens.

\begin{tabular}{cccc}
\hline Specimens & Condition & $\begin{array}{c}P_{\max } \\
(\mathrm{kN})\end{array}$ & $\begin{array}{c}\mathrm{CoV} \\
(\%)\end{array}$ \\
\hline \multirow{2}{*}{ GFRP-brick } & Reference & 10.0 & 5.3 \\
\cline { 2 - 4 } & Aged & 9.4 & 20.6 \\
\hline \multirow{2}{*}{ SRG-brick } & Reference & 4.1 & 14.4 \\
\cline { 2 - 4 } & Aged & 3.0 & 20.0 \\
\hline
\end{tabular}


Table 3. Fracture energy and AE energy in different failure modes for GFRP-strengthened specimens.

\begin{tabular}{|c|c|c|}
\hline $\begin{array}{l}\text { Failure } \\
\text { mode }\end{array}$ & $\begin{array}{c}G_{\text {f-ave. }} \\
(\mathrm{N} / \mathrm{mm})\end{array}$ & $\begin{array}{c}E_{\text {cum. }} \\
\text { (eu) }\end{array}$ \\
\hline Cohesive* & 0.60 & $4.20 \mathrm{E}+08$ \\
\hline Adhesive** & 0.40 & $7.20 \mathrm{E}+07$ \\
\hline
\end{tabular}




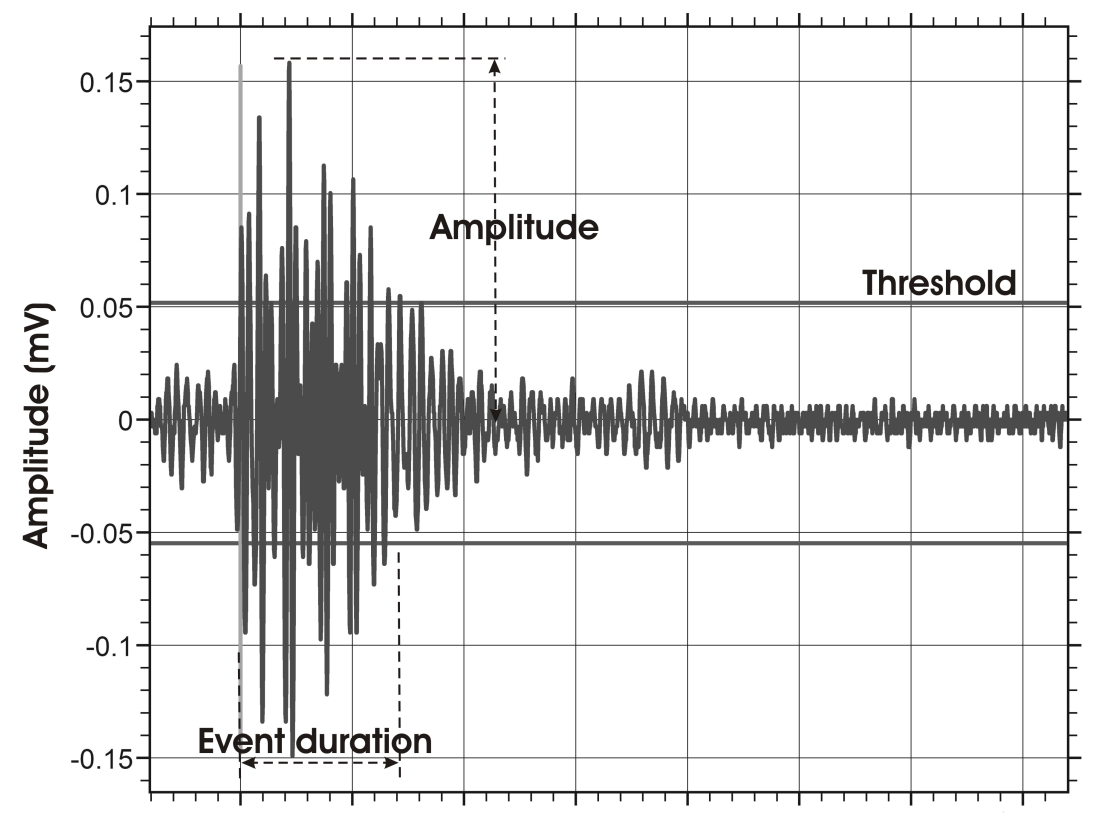

Fig.1. Typical AE transient event with indication of wave characteristics. 


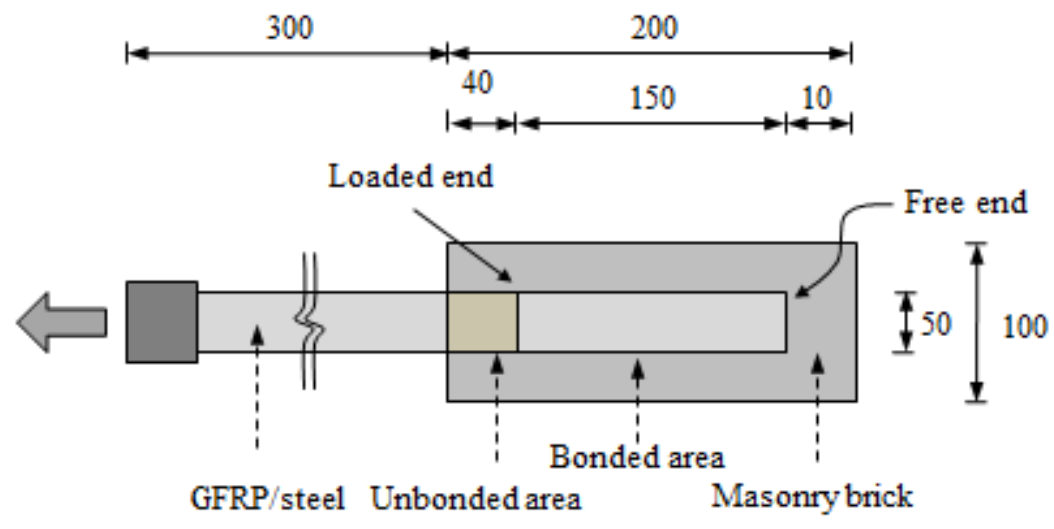

Fig.2. Details of the specimens prepared for debonding tests (dimensions in $\mathrm{mm}$ ): Plan view. 


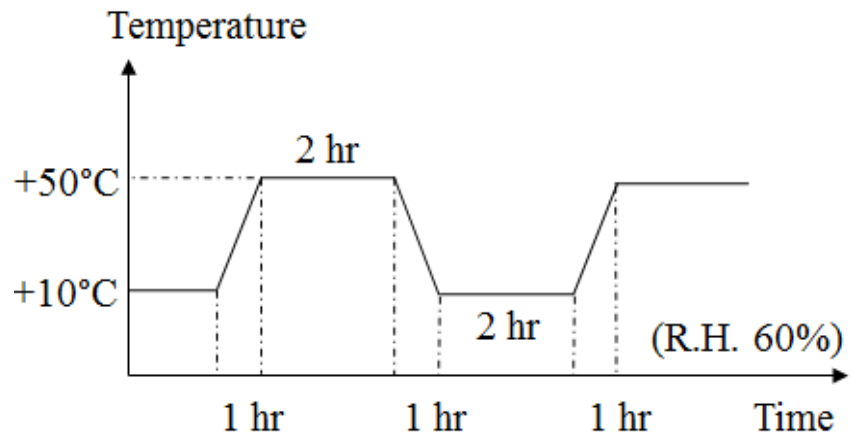

Fig.3. Hygrothermal exposure. 

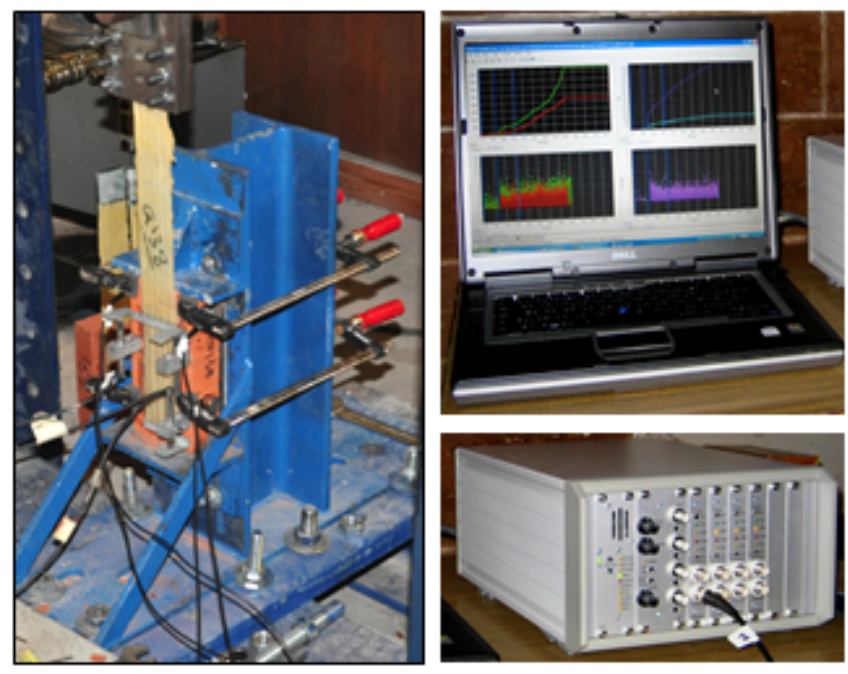

(a)

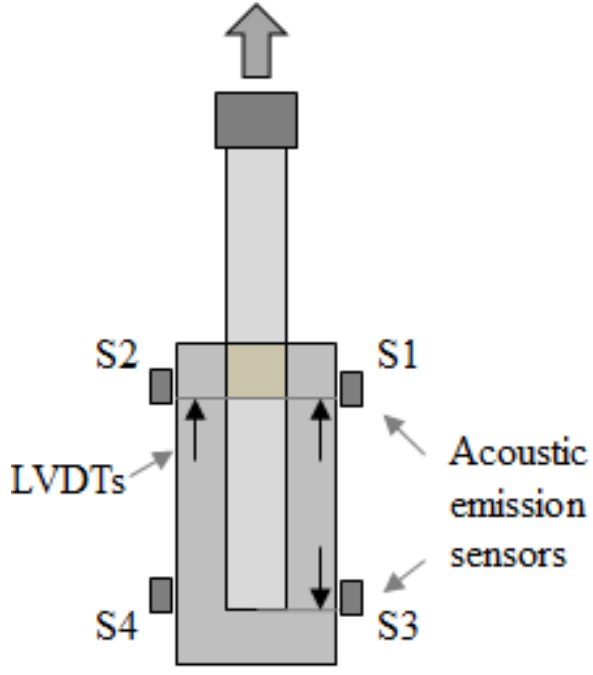

(b)

Fig.4. (a) Test setup; (b) test instrumentation. 


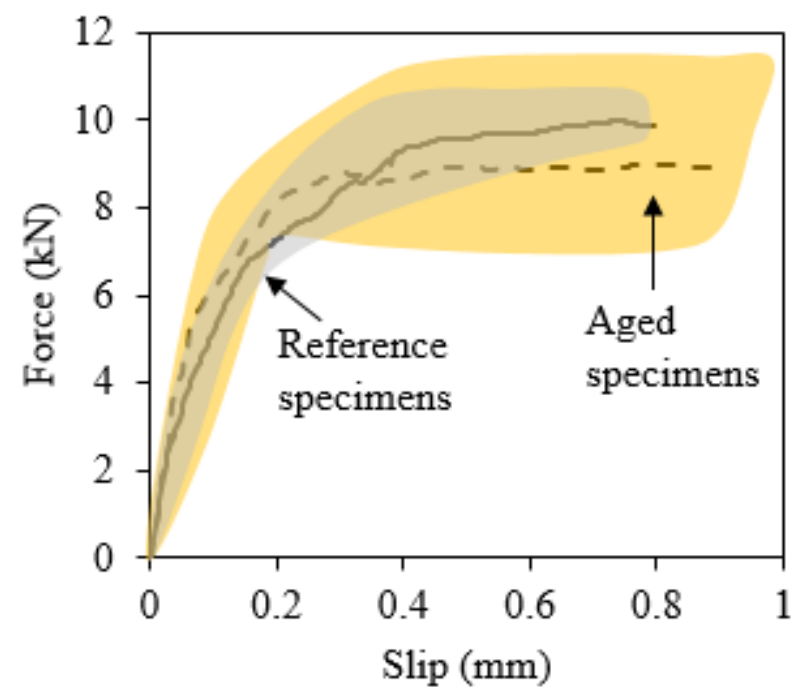

(a)

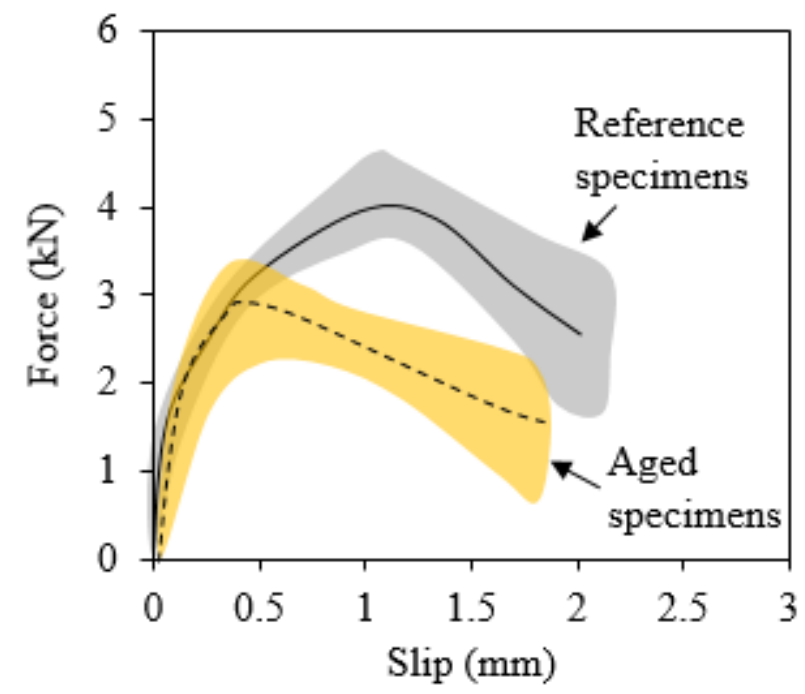

(b)

Fig.5. Envelope of experimental force-slip behavior in the reference and aged specimens: (a) GFRP-strengthened bricks; (b) SRG-strengthened bricks. 


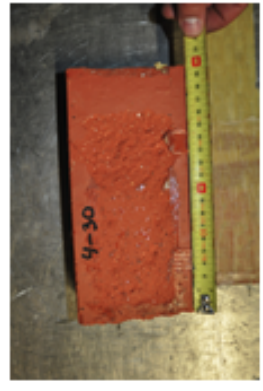

(a)

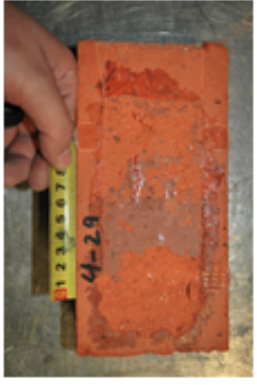

(b)

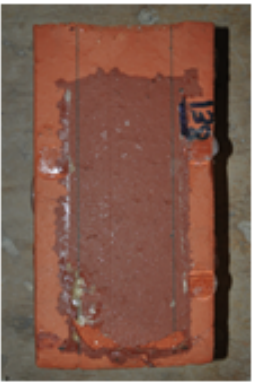

(c)

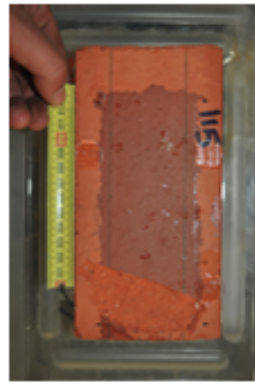

(d)

Fig.6. Observed failure modes in GFRP-strengthened brick specimens: (a) cohesive failure with fracture inside brick; (b) cohesive-adhesive failure; (c) adhesive failure at the FRP/brick interface; (d) adhesive failure with a brick bulb at the free end. 


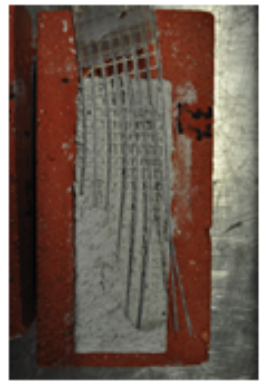

(a)

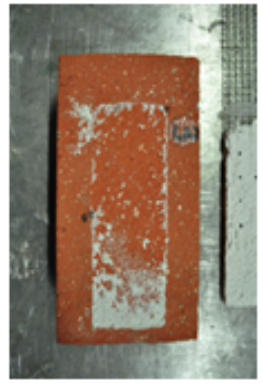

(b)

Fig.7. Observed failure modes in SRG-strengthened brick specimens: (a) steel fibers slipping and mortar cover separation; (b) mortar-brick interface debonding 


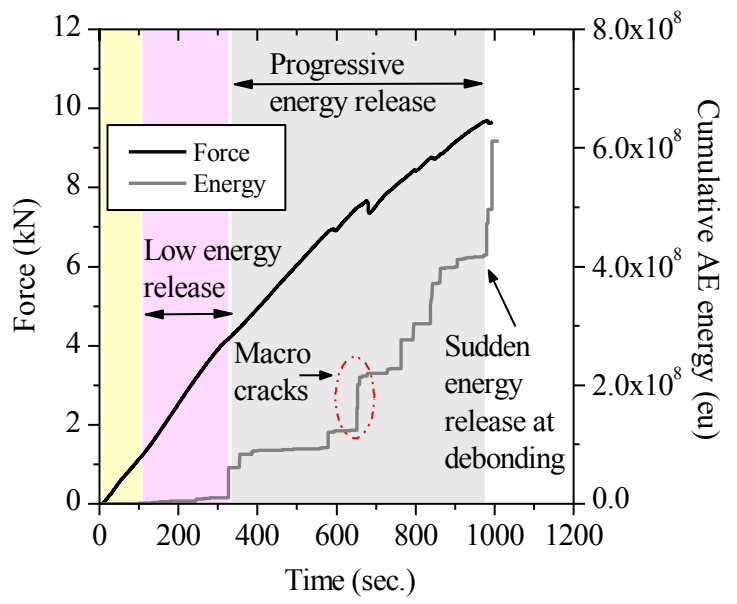

(a)

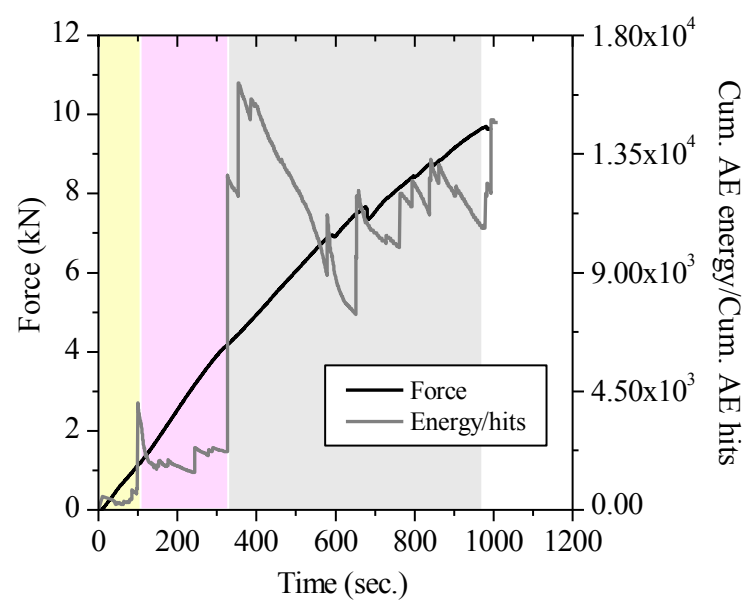

(c)

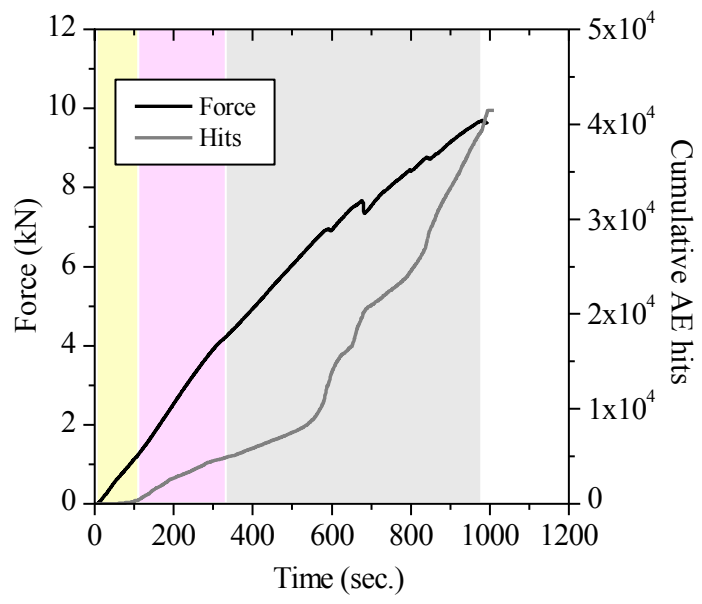

(b)

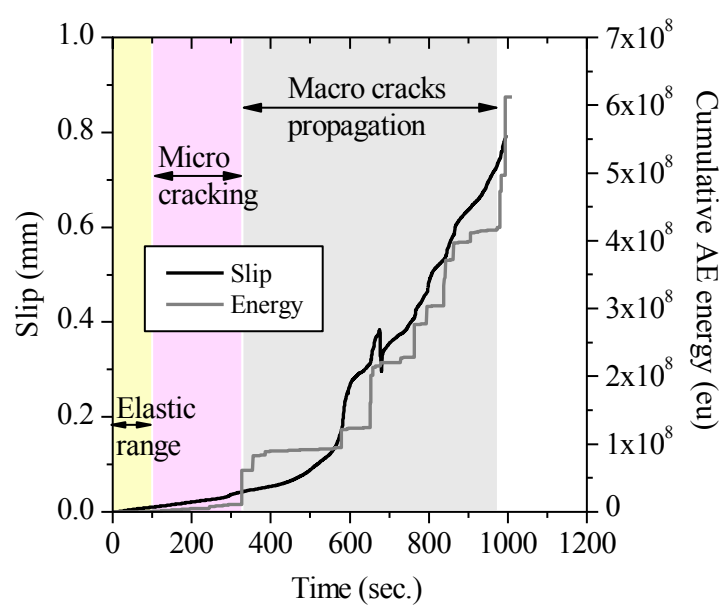

(d)

Fig.8. Typical AE results in reference GFRP-strengthened brick specimens: (a) force-cumulative AE energy; (b) force-cumulative AE hits; (c) force-energy/hits, E/h; (d) slip-cumulative AE energy. 

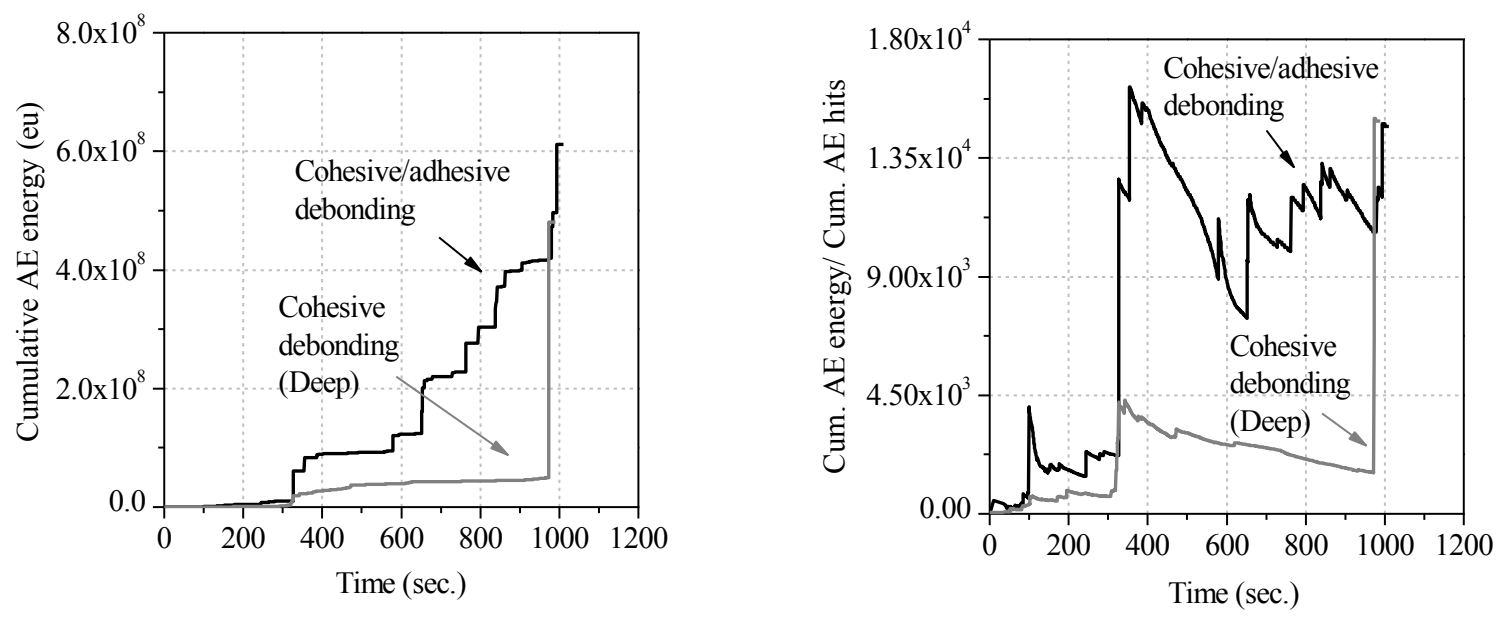

(a)
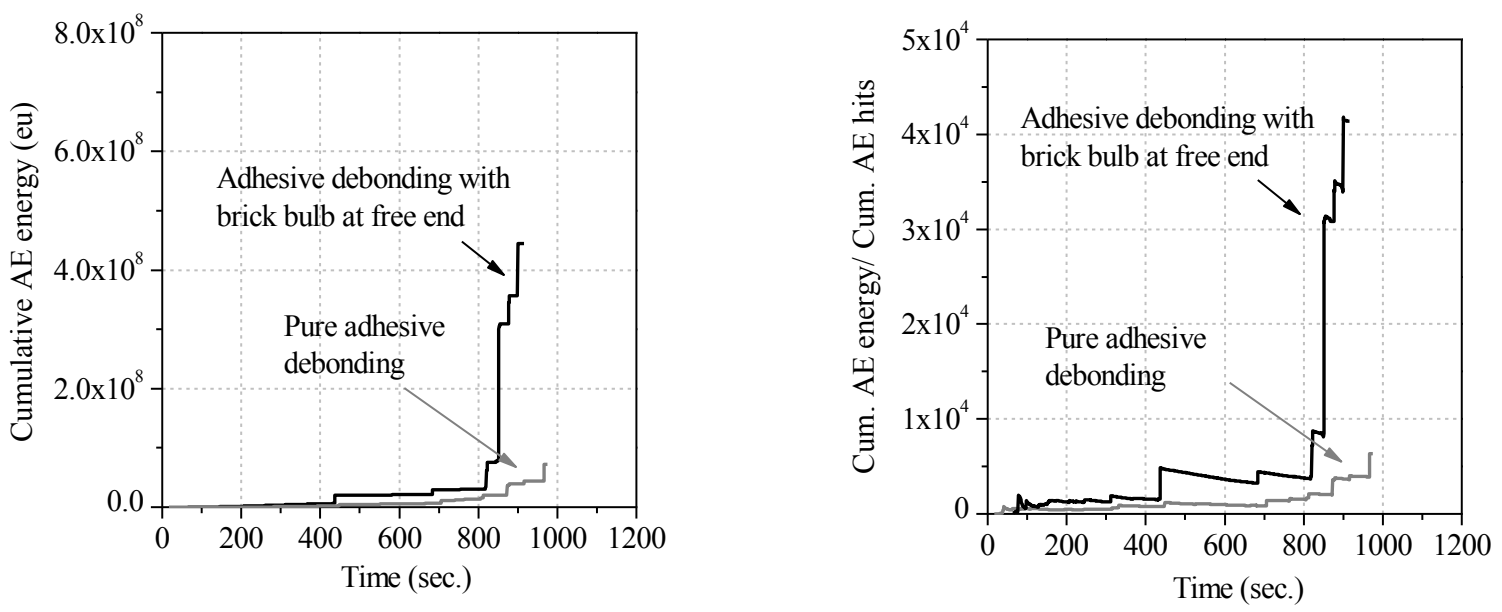

(b)

Fig.9. Comparison of different failure modes in GFRP-strengthened bricks: (a) cohesive debonding; (b) adhesive debonding. 


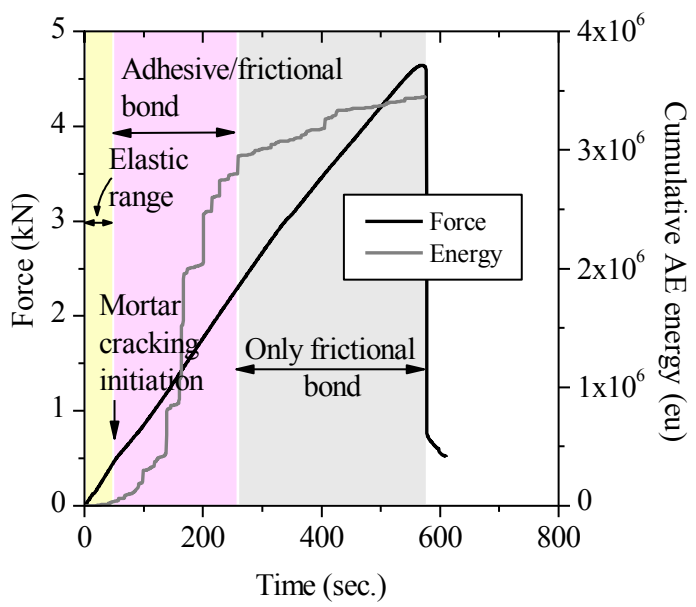

(a)

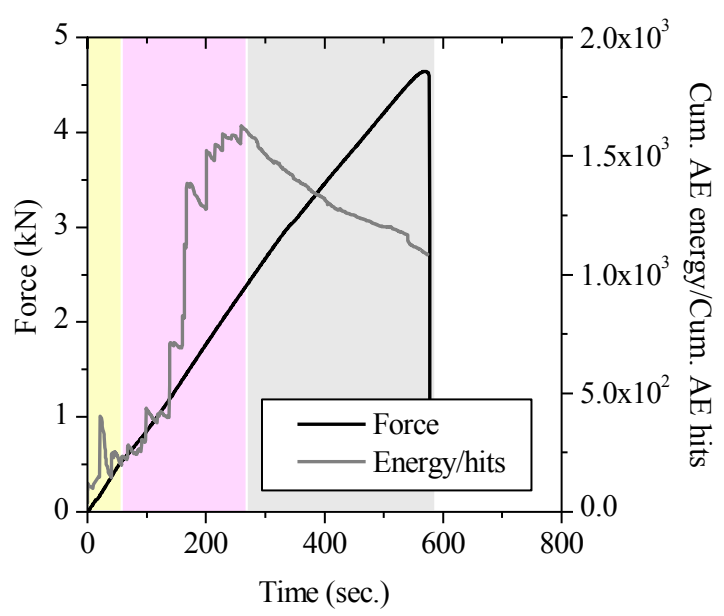

(c)

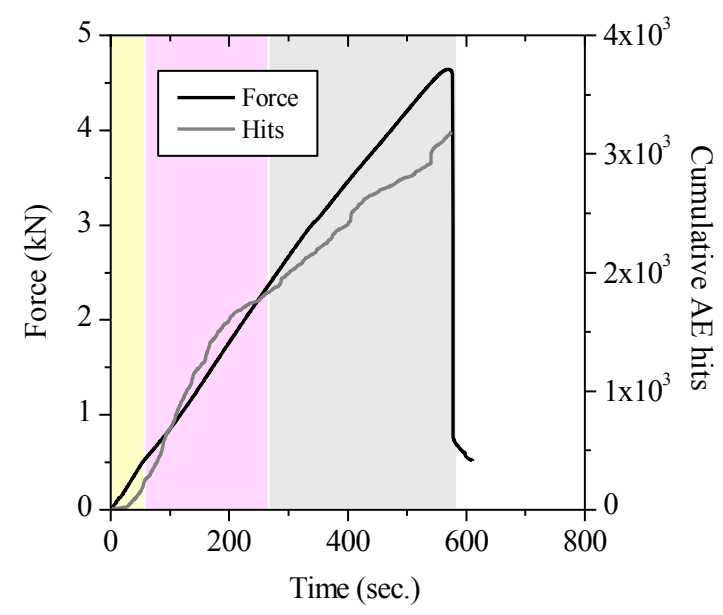

(b)

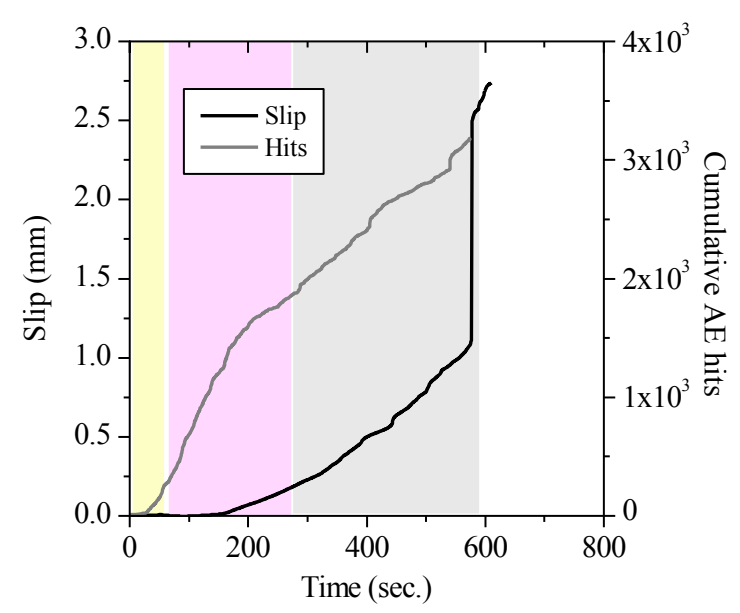

(d)

Fig.10. Typical AE results in reference SRG-strengthened brick specimens: (a) force-cumulative AE energy; (b) force-cumulative AE hits; (c) force-energy/hits, E/h; (d) slip-cumulative AE energy. 


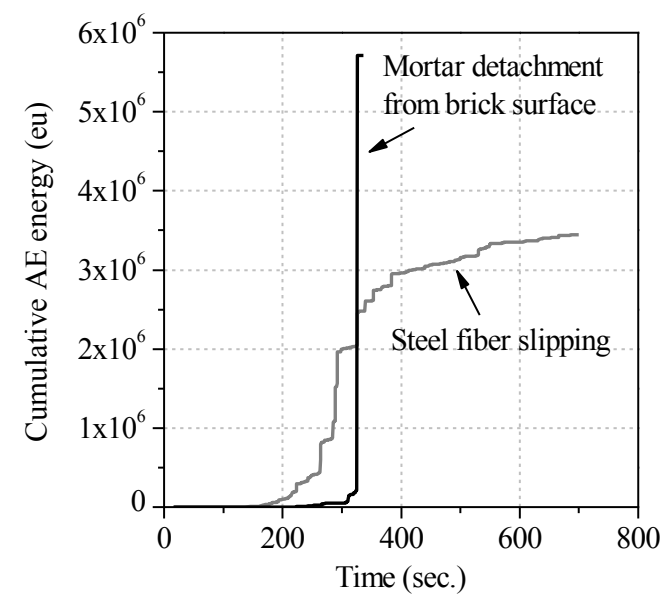

(a)

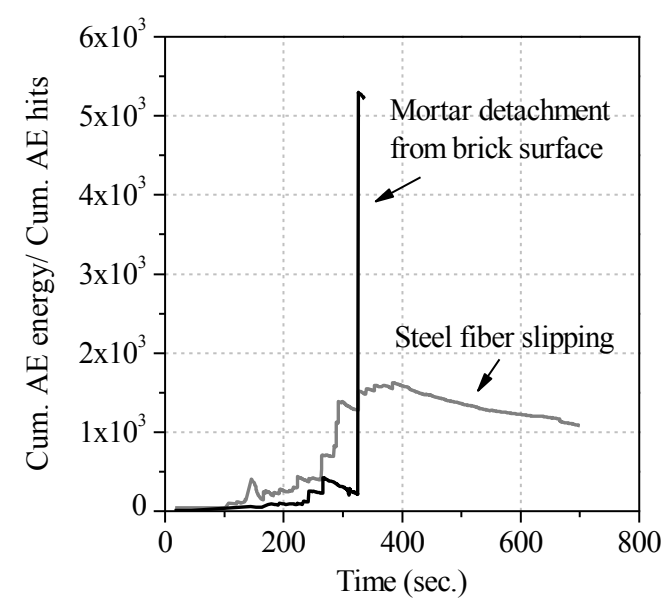

(b)

Fig.11. Comparison of different failure modes in SRG-strengthened bricks: (a) cumulative AE energy; (b) E/h ratio. 


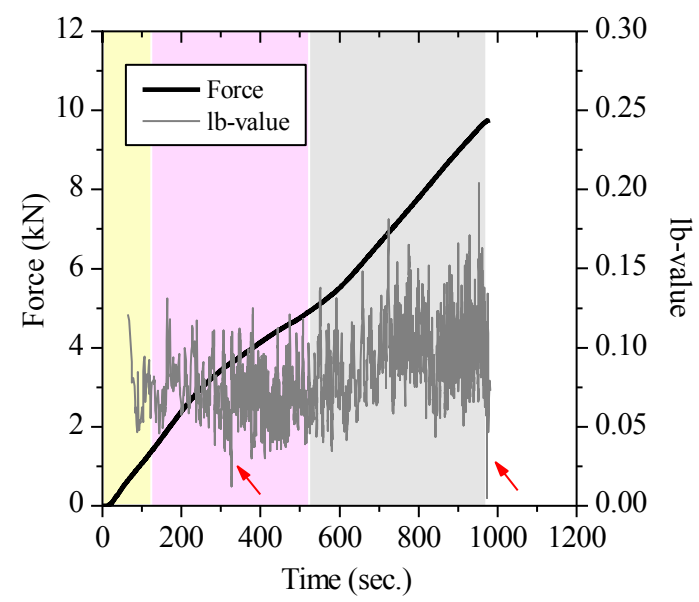

(a)

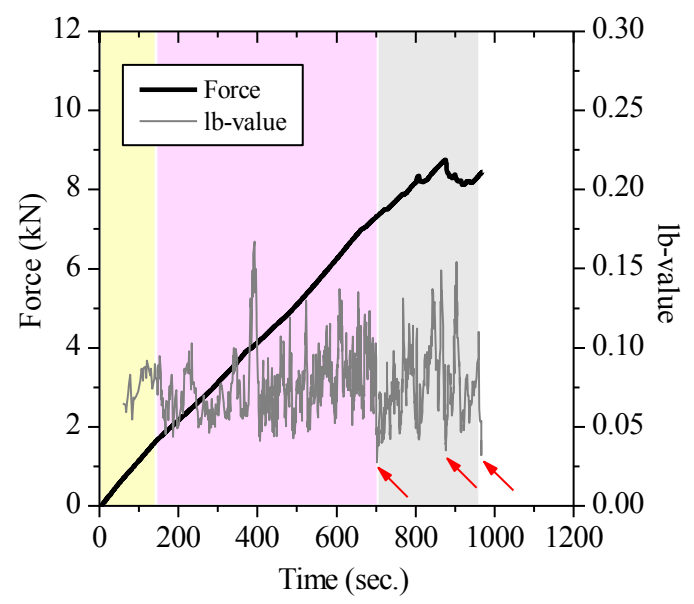

(c)

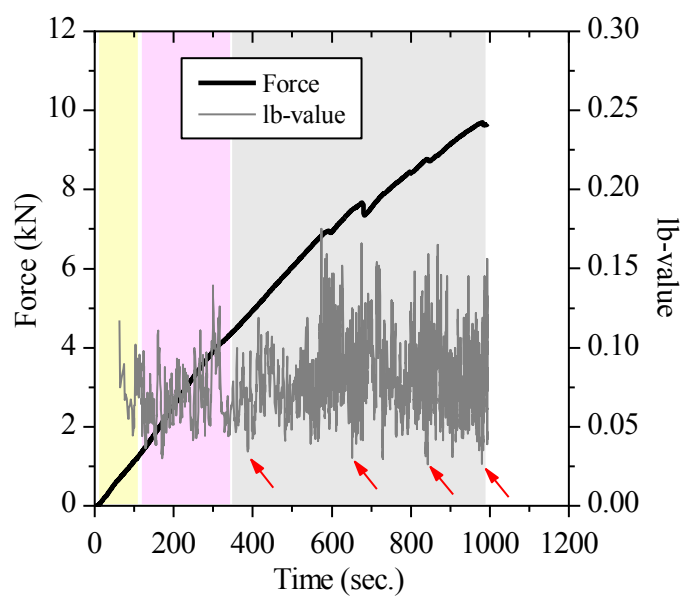

(b)

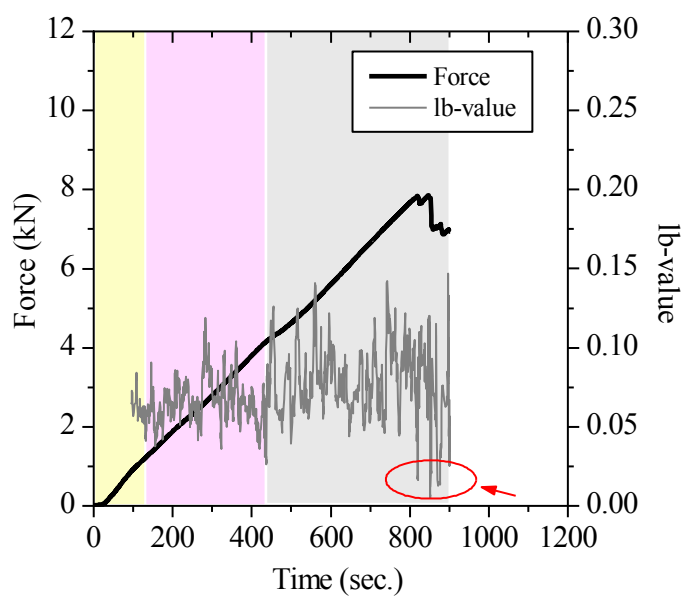

(d)

Fig.12. Ib-value analysis for GFRP-strengthened brick specimens with (a) cohesive failure; (b) cohesive/adhesive failure; (c) adhesive failure; (d) adhesive failure with brick bulb. 


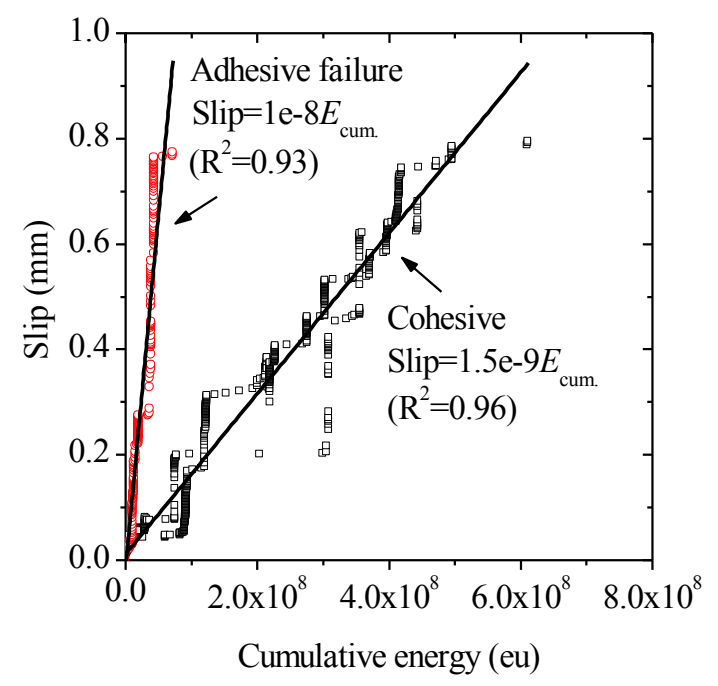

Fig.13. Correlations between slip and cumulative AE energy in GFRP-strengthened specimens. 